E3S Web of Conferences 1, 19004 (2013)

DOI: $10.1051 / \mathrm{e} 3$ sconf/20130119004

(c) Owned by the authors, published by EDP Sciences, 2013

\title{
Heavy Metals in the Ground Surface Dust and Agricultural Soil in Artisanal and Medium-scale Zinc Smelting Area in Northwest Guizhou Province, China
}

\author{
Z. G. Li ${ }^{1}$, X. B. Feng ${ }^{1}$, X. Y. Bi ${ }^{2,3}$, G. Y. Sun ${ }^{4}$, J. M. Zhu ${ }^{1}$, H. B. Qin ${ }^{1,5}$, L. H. Shang ${ }^{1}$ and B. Meng ${ }^{1}$ \\ ${ }^{1}$ State Key Laboratory of Environmental Geochemistry, Institute of Geochemistry, Chinese Academy of Sciences, \\ Guiyang 550002, China, lizhonggen@vip.skleg.cn, fengxinbin@vip.skleg.cn, zhujianming@vip.skleg.cn, \\ shanglihai@vip.skleg.cn, mengbo05@gmail.com \\ ${ }^{2}$ Key Laboratory of Biogeology and Environmental Geology, China University of Geosciences, Wuhan 430074, China, \\ bixy@cug.edu.cn \\ ${ }^{3}$ Faculty of Earth Science, China University of Geosciences, Wuhan 430074, China, bixy@cug.edu.cn \\ ${ }^{4}$ Hei Longjiang Institute of Geological survey, Harbin 150036, China, wuqigysun@163.com \\ ${ }^{5}$ Graduate School of Chinese Academy of Sciences, Beijing 100049, China, qinhaibo@mails.gyig.ac.cn
}

\begin{abstract}
Twenty heavy metals in the ground surface dust and agricultural soil in three different areas, i.e., a former artisanal zinc smelting area, a medium-scale zinc smelting area, and a control area, in Guizhou province southwest China, were investigated to reveal the pollution status of these heavy metals. The results showed that the pollution was most serious in the artisanal zinc smelting area, followed by the medium-scale zinc smelting area, while the control area was relatively clean. Zinc smelting activities had caused environmental contamination for elements such as $\mathrm{Ag}, \mathrm{As}, \mathrm{Bi}, \mathrm{Cd}, \mathrm{Cu}, \mathrm{Hg}, \mathrm{In}, \mathrm{Pb}, \mathrm{Sb}, \mathrm{Sn}, \mathrm{Zn}$. Whereas, $\mathrm{Co}, \mathrm{Cr}$, $\mathrm{Ga}, \mathrm{Mo}, \mathrm{Ni}, \mathrm{Sc}, \mathrm{Th}, \mathrm{Tl}, \mathrm{V}$ were in the natural levels, hinting they were irrelevant to the zinc smelting activities. Concentrations of most heavy metals that come from the zinc smelting were obviously higher in the ground surface dust than that in the agricultural soil. And $\mathrm{Cd}, \mathrm{Pb}, \mathrm{Zn}, \mathrm{Ag}$ were the four elements that affected by the zinc smelting activities most.
\end{abstract}

Key words: Heavy metals, zinc smelting, pollution assessment, dust, soil

\section{Introduction}

Zinc smelting is one of important source for heavy metals into the environment, due to quantities of heavy metals are associated with the ores. This study tries to unveil the heavy metal pollution status in Guizhou province, southwest China, from the zinc smelting activities. Two smelting area, namely, a artisanal zinc smelting area and a medium-sized zinc smelting area, as well as a control area, were selected to probe the environment quantity in terms of heavy metals.

\section{Materials and Methods}

Samples, including ground surface dust and agricultural soils, were taken from three areas in Guizhou from 2008 to 2009. The artisanal zinc smelting area is Xin-Guan-Zhai (XGZ) in Magu town, Hezhang county, northwest Guizhou, totally 37 ground dusts and 14 agricultural soils were taken there. The medium-sized zinc smelter is located around the city of Hezhang county (HZX), northwest Guizhou, and totally 30 street dusts and 28 agricultural soils were taken. And the control area is in suburb of Guiyang city, Huaxi district (HX), and 3 street dusts, 3 agricultural soils, and 15 rural ground dusts (LZ) were collected. 20 heavy metals were analyzed, $\mathrm{Hg}$ and As were determined by CVAFS, while other elements were detected by ICP-MS.

Heavy metal pollution assessment was conducted by geoaccumulation index, which is computed using the following equation:

$\mathrm{I}_{\mathrm{geo}}=\log _{2}\left(\mathrm{C}_{\mathrm{n}} / 1.5 \mathrm{~B}_{\mathrm{n}}\right)$

Where $C_{n}$ is the measured concentration of the heavy metal in the samples, $B_{n}$ is the geochemical background value in soil in Guizhou. The $\mathrm{I}_{\text {geo }}$ is classified as seven groups, uncontaminated $\left(\mathrm{I}_{\text {geo }} \leq 0\right)$; uncontaminated to 


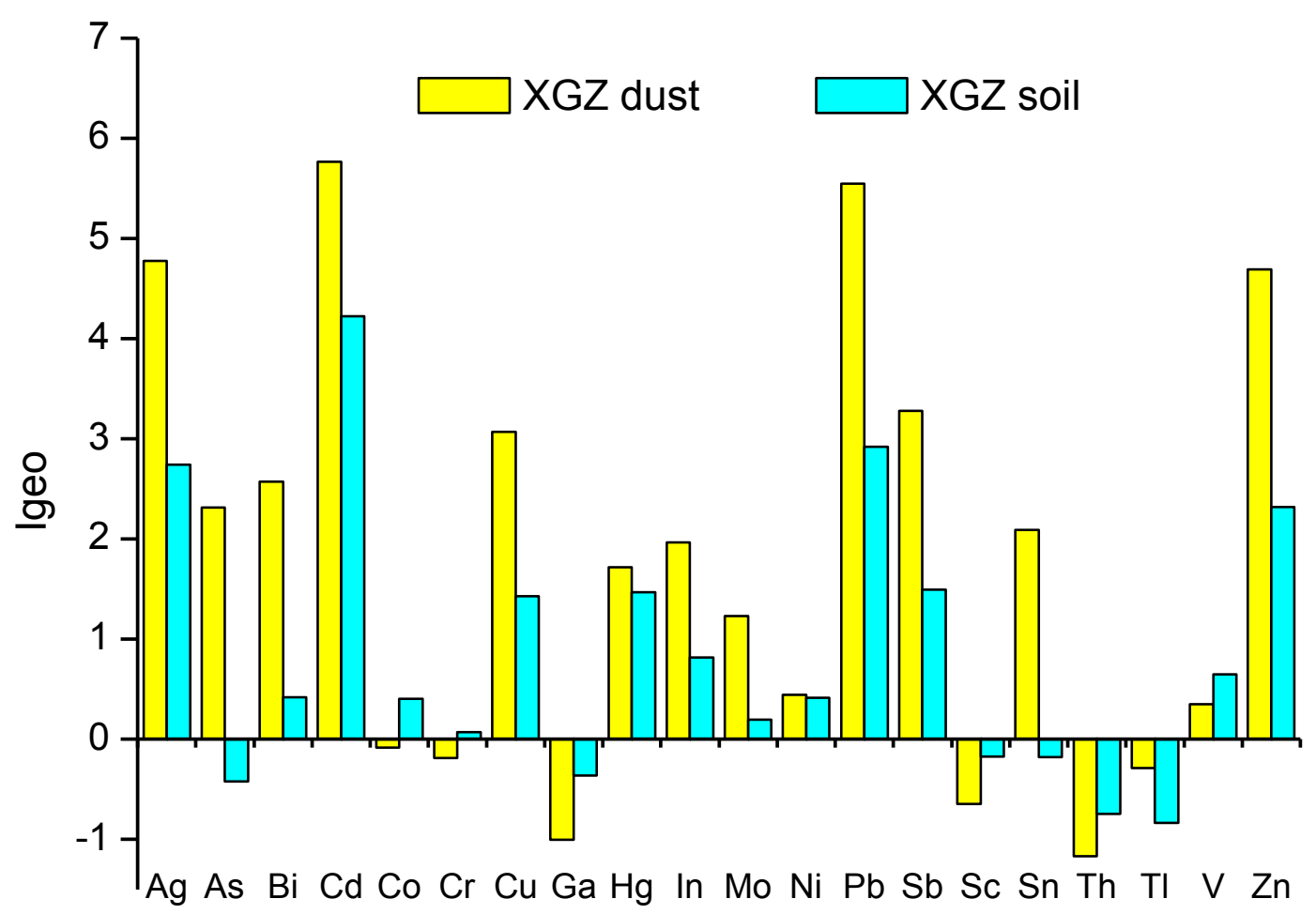

Fig. 1. Geoaccumulation index $\left(\mathrm{I}_{\text {geo }}\right)$ of twenty heavy metals in the ground surface dust and agricultural soil in the artisanal zinc smelting area (Xin-guan-zhai)

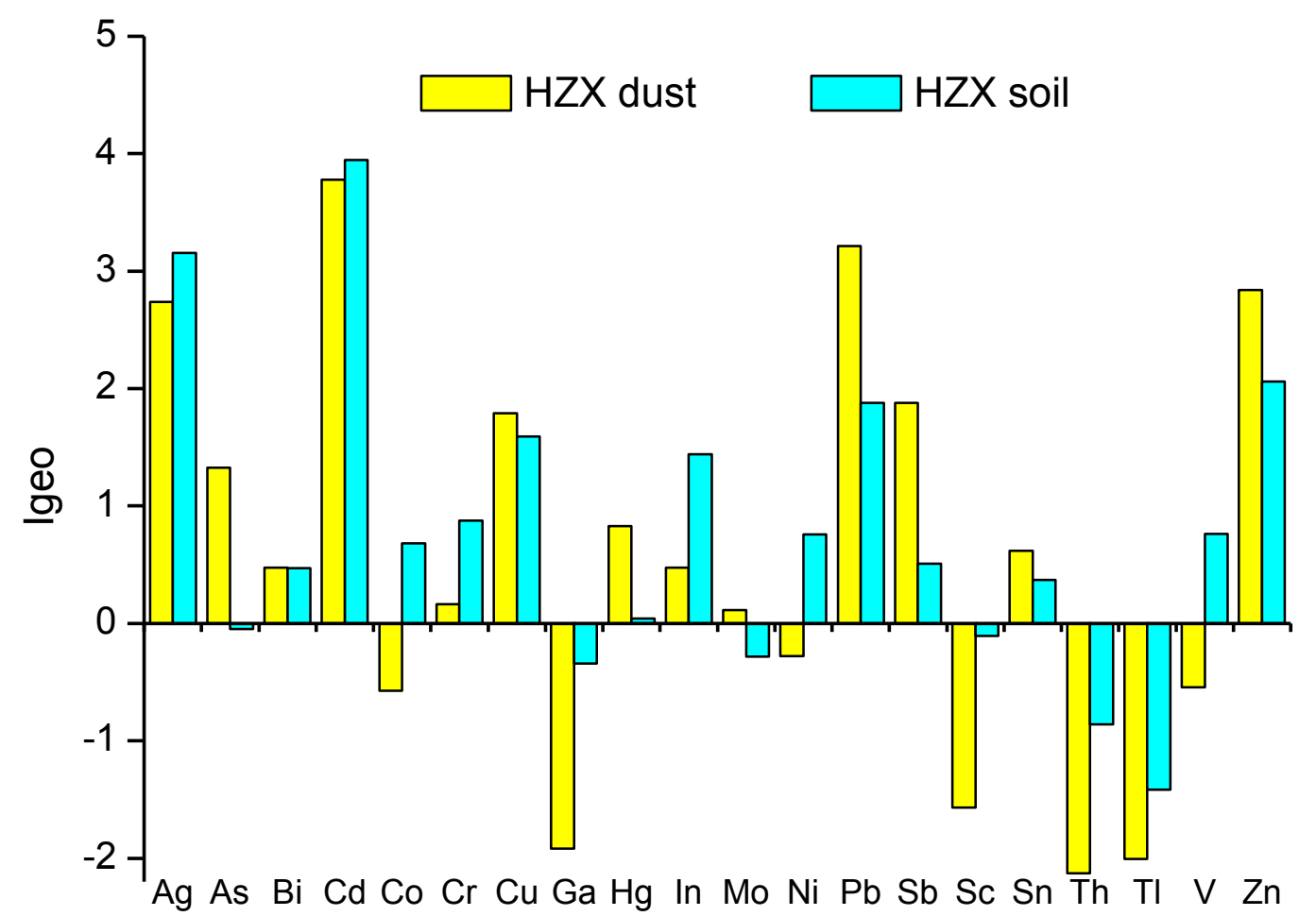

Fig. 2. Geoaccumulation index $\left(I_{g e o}\right)$ of twenty heavy metals in the ground surface dust and agricultural soil in the medium-scale zinc smelting area (He-Zhang-Xian) 


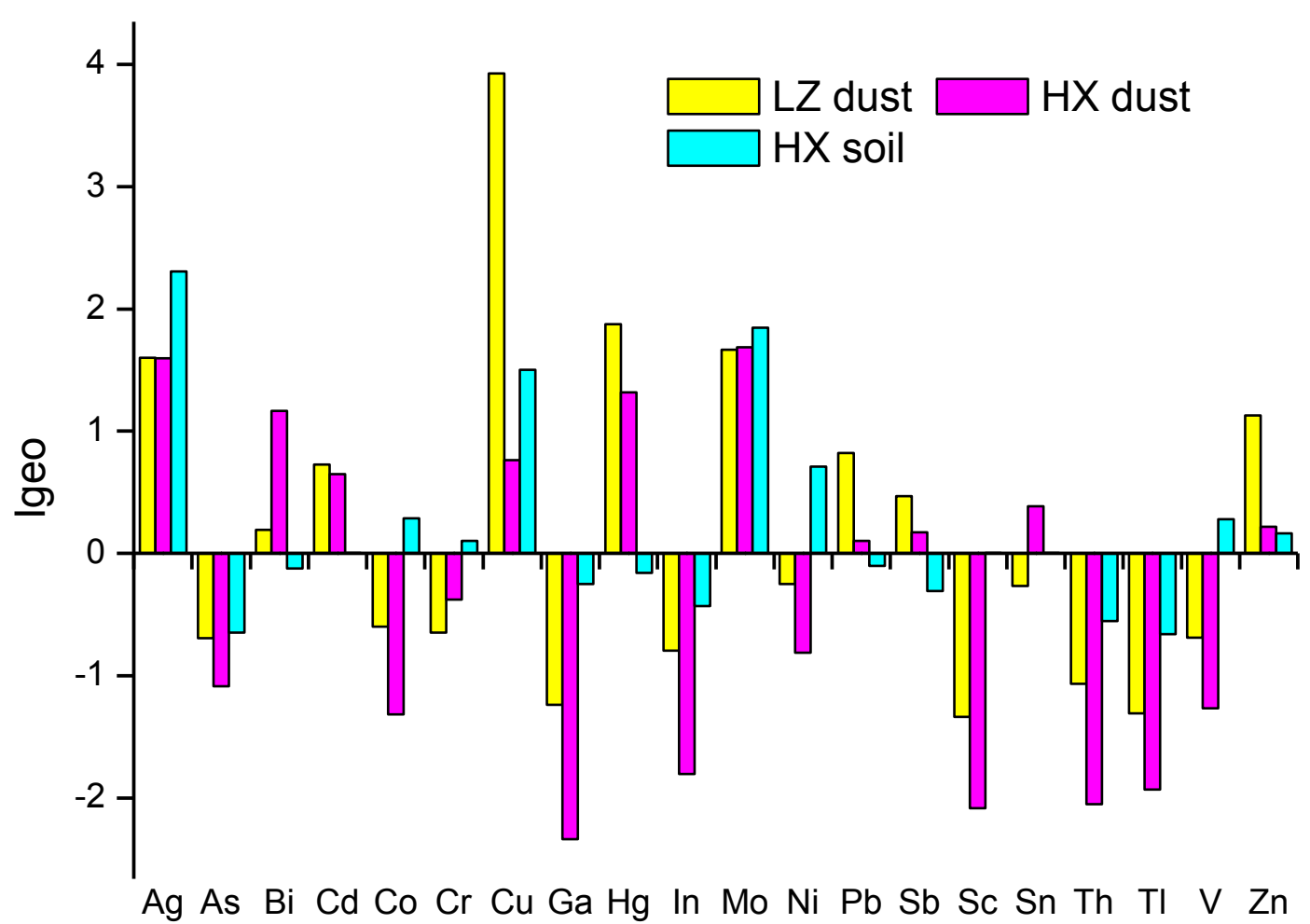

Fig. 3. Geoaccumulation index $\left(\mathrm{I}_{\text {geo }}\right)$ of twenty heavy metals in the ground surface dust and agricultural soil in the control area (Hua-Xi and Lei-Zhuang)

moderately contaminated $\quad\left(0<\mathrm{I}_{\text {geo }} \leq 1\right) ; \quad$ moderately contaminated $\left(1<\mathrm{I}_{\text {geo }} \leq 2\right)$; moderately to heavily contaminated $\left(2<\mathrm{I}_{\text {geo }} \leq 3\right)$; heavily contaminated $\left(3<\mathrm{I}_{\text {geo }} \leq 4\right)$; heavily to extremely contaminated $\left(4<\mathrm{I}_{\text {geo }} \leq 5\right)$; extremely contaminated $\left(\mathrm{I}_{\mathrm{geo}}>5\right)$.

\section{Results and Discussion}

The result of heavy metal pollutions in the three areas were shown in Fig. 1 to Fig. 3. It can be seen that both artisanal and medium-scale zinc smelting has caused heavy metal pollutions for elements of $\mathrm{Ag}, \mathrm{As}, \mathrm{Bi}, \mathrm{Cd}$, $\mathrm{Cu}, \mathrm{Hg}$, In, Pb, Sb, Sn, Zn. Whereas, Co, Cr, Ga, Mo, Ni, Sc, Th, Tl, V seems doesn't affected by the zinc smelting, hinting they were from the natural source. Artisanal zinc smelting area is most contaminated, followed by the medium-scale zinc smelting area, while for the control area it was relatively clean. Concentrations of heavy metals that come from the zinc smelting were obviously higher in the ground surface dust than that in the agricultural soil. And $\mathrm{Cd}, \mathrm{Pb}, \mathrm{Zn}, \mathrm{Ag}$ were the four elements that affected by the zinc smelting activities most, the average concentration of $\mathrm{Cd}, \mathrm{Pb}, \mathrm{Zn}, \mathrm{Ag}$ in the ground dust in the artisanal zinc smelting area were $25.6 \mathrm{mg} \mathrm{kg}^{-1}$, $2065 \mathrm{mg} \mathrm{kg}^{-1}, \quad 3488 \mathrm{mg} \mathrm{kg}^{-1} \quad 2.8 \mathrm{mg} \mathrm{kg}^{-1}$, respectively, and possible adverse health problem were exist in such area.

\section{Conclusion}

Artisanal smelting caused more pollution than the medium-scale zinc smelting for elements $\mathrm{Ag}, \mathrm{As}, \mathrm{Bi}, \mathrm{Cd}$, $\mathrm{Cu}, \mathrm{Hg}, \mathrm{In}, \mathrm{Pb}, \mathrm{Sb}, \mathrm{Sn}, \mathrm{Zn}$. And $\mathrm{Cd}, \mathrm{Pb}, \mathrm{Zn}, \mathrm{Ag}$ were the most contaminated heavy metals.

\section{Acknowledgements}

This study was financially supported by the National Natural Science Foundation of China (No.40703023, 40903041, 21077103) and the Government of Norway (Sino-Norwegian cooperation project "Capacity building for reducing mercury pollution in China-Case study in Guizhou province"). 